\title{
Market Structure of Scooter Segment of Two Wheeler Industry in India
}

\author{
Dr. Agrim Verma \\ Assistant Professor, Goswami Ganesh Dutta Sanatan Dharma College, Chandigarh \\ E-mail: agrimverma.ubs@gmail.com
}

\begin{abstract}
Transportation system of a country has a noteworthy role to play in the development of an economy and its sectors. Automobile sector occupies a prominent place in the fabric of Indian economy. Presently, India has already touched the threshold of a major take off in the next decade and beyond to becoming one of the largest automotive (vehicle and component makers) manufacturers in the world. The objective of study was to measure the market structure of scooter segment of two wheeler industry in India for eight financial years, i.e. from the year 2011-12 to the year 2018-19. Descriptive analysis was conducted to present a profile of the industry which included analysis of average, standard deviation, compound annual growth rate, frequency, percentage of data value for each of the variables. The results of the study revealed that overall, there is existence of oligopoly form of market structure in the scooter segment of two wheeler industry in India.
\end{abstract}

Keywords: Market Structure, Market Concentration, Two Wheeler Industry, Scooter, India

\section{Introduction and Review of Literature}

Transportation system of a country has a noteworthy role to play in the development of an economy and its sectors. Automobile sector occupies a prominent place in the fabric of Indian economy. It is believed that the automobile industry in India has emerged as a sunrise sector in the Indian economy in last two decades of its development. The automobile industry has proved to be a building block of the Indian economy and a key driver of macroeconomic growth of Indian economy (Government of India, Automotive Sector: Achievements Report, 2016).

(Porter, 1979) in his study discussed the factors influencing concentration in an industry and how the competitive forces operating in an industry influenced the strategy formulation practices for a business firm. The author elaborated on the competitive forces, namely, bargaining power of suppliers, bargaining power of buyers, threat of substitute products, and threat of potential entrants to an industry and level of rivalry among existing players in an industry. The author stressed that the cumulative strength of all these above stated factors determined the strength of competitiveness and further helped a firm in devising strategies.

(Porter, 1981) in his study stressed on cross-fertilisation of the fields of Industrial Organisation and Business Policy for assessing competition in an industry, strategic choices and impact on performance. Further, the author also elaborated on the Structure-Conduct-Performance paradigm. According to the structure-conduct-performance paradigm, market structure 
determined the conduct (strategy) of business firms in an industry, and market structure and conduct jointly influenced performance of firms in an industry.

(White A. P., 1982) applied measures to calculate market structure of banking industry. The author highly focused on the significance of number of sellers in a market and their relative size distribution in deciding market structure. The author calculated correlation coefficients between measures of market structure, i.e. concentration ratio, Herfindahl index, Entropy index and Gini coefficient.

(Porter, 1983) emphasised on the purpose of business strategy so that internal competences of a business firm can be aligned with the external business environment a firm operates in. For this, the author stressed on the need for developing a competitive analysis framework.

(Ferguson \& Ferguson, 1994) explained and compared multiple measures for calculating market concentration. The absolute measures for measuring market concentration included concentration ratio, Herfindahl-Hirschman index, Hannah and Kay index, Entropy index. The relative measures for measuring market concentration included variance of the logarithms of firm size and Gini coefficient. The authors also discussed the theoretical considerations in applying these measures of concentration. The authors concluded that although there are limitations associated with measures of market concentration which make them insubstantial to be able to convey the complexities of changing business environment of an industry but there is no denying that these measures of concentration provide useful information about the market structure of an industry.

(Kramaric \& Kitic, 2012) analysed the market structure through the degree of concentration of insurance markets in new EU member states. The authors applied most commonly used and widely accepted concentration indicators, i.e., concentration ratio, Herfindahl - Hirschman index and entropy index for the years 2000 to 2010. The results indicated downward trend in terms of concentration but the level of concentration varied significantly among the countries.

\section{Research Methodology and Conceptual Framework}

The word "structure" according to (Cambridge Dictionary) means "the way in which the parts of a system or objects are arranged or organised, or a system arranged in this way". The term "market structure" thus refers to the manner in which firms are organised or interrelated (White, 1982). The present study was undertaken with an aim to study the market structure of scooter segment of two wheeler industry in India. Market Structure is defined as the number and distribution of firms in a market. Market structure for an industry can range from perfect competition at one end of the spectrum to monopoly form of market structure at other end of the spectrum (Besanko et al, 2013).

The raw data for the study was obtained from Society of Indian Automobile Manufacturers (SIAM) for eight financial years, i.e. from the year 2011-12 to the year 2018-19. In India, eight sellers are operating in the scooter segment of two wheeler industry in India. Descriptive analysis was conducted to present a profile of the industry which included analysis of average, standard deviation, compound annual growth rate, frequency, percentage of data value for each of the variables. 


\subsection{Objective of the Study}

The research objective of the study was to measure market structure of scooter segment of two wheeler industry in India.

\subsection{Measurement of Market Concentration}

There are various measures to measure market concentration, however, in the opinion of most of the economists, the most important measures to measure market concentration include $\mathrm{p}$ firm Concentration Ratio (CR), Herfindahl-Hirschman Index (HHI), Entropy Index $€$, Gini Ratio (GR), Hannah and Kay Index (HKI), Lerner Index (LI), Variance of Logs (VL), Comprehensive Concentration Index (CCI), Hall-Tideman Index (HTI). For the purpose of present study, three measures of concentration have been applied for calculating market structure in two wheeler industry because of their wide acceptance and utility. The three measures of market concentration used are p-firm Concentration Ratio (CR), HerfindahlHirschman Index (HHI), and Entropy Index (E). There are lots of additional measures with alternative weights but these three measures are the most commonly used.

2.2.1 p-firm Concentration Ratio (CR): According to (Ferguson \& Ferguson, 1994), Concentration Ratio is defined as cumulative share of the largest firms in an industry. For the purpose of standard Concentration Ratio, weights of unity are assigned to the share of $p$ largest firms in an industry, with the share of all other firms within the industry receiving a weight of zero (Jacquemin \& Berry, 1979). The ratio is represented as follows in symbolic form:

$$
\mathrm{CR}_{\mathrm{p}}=\sum_{i=1}^{p} S i
$$

where,

$\mathrm{CR}_{\mathrm{p}}=\mathrm{p}$-firm Concentration Ratio

$\mathrm{p}=$ Number of largest firms included

$S_{i}=$ Share of $i^{\text {th }}$ firm in descending order

2.2.2 Herfindahl-Hirschman Index (HHI): According to (Ferguson \& Ferguson, 1994), Herfindahl-Hirschman Index is defined as the sum of squares of relative shares of all the firms in an industry. According to (Jacquemin \& Berry, 1979), in case of this index, the share of each firm is weighed by itself. This index is highly accepted and used because of its bounded properties, ease of understanding and intuitive appeal (Jacquemin \& Berry, 1979). The index is represented as follows in symbolic form:

where,

$$
\mathrm{HHI}=\sum_{i=1}^{n}(X i)^{2}
$$

$\mathrm{HHI}=$ Herfindahl-Hirschman Index

$\mathrm{n}=$ Number of firms in the industry

$\mathrm{X}_{\mathrm{i}}=$ Market share of $\mathrm{i}^{\text {th }}$ firm

\subsubsection{Entropy Index}

Entropy Index is another measure for calculating market concentration. The relationship between Entropy Index and market concentration is inverse. Higher the value of Entropy Index, the lower the level of concentration and vice versa. In symbolic form, the index is represented as shown below (Jacquemin \& Berry, 1979). 
where,

$$
\mathrm{E}=\sum_{i=1}^{n} S i \log \left(\frac{1}{S i}\right)
$$

$\mathrm{E}=$ Entropy Index

$\mathrm{S}_{\mathrm{i}}=$ Market share of $\mathrm{i}^{\text {th }}$ firm

$\mathrm{n}=$ Number of firms

\section{Findings and Analysis}

The Findings and Analysis included measurement of market concentration firstly, overall, for the scooter segment followed by measurement of market concentration for different categories of scooter segment segregated on the basis of engine capacity (cubic capacity/cc). Therefore, the analysis of market structure of scooter segment of two wheeler industry in India has been divided into following sections:

- Scooter segment (Overall)

- Scooter category with engine capacity $\leq 75 \mathrm{cc}$

- Scooter category with engine capacity $>75$ cc but $\leq 90$ cc

- Scooter category with engine capacity $>90 \mathrm{cc}$ but $\leq 125 \mathrm{cc}$

- Scooter category with engine capacity $>125 \mathrm{cc}$ but $\leq 150 \mathrm{cc}$

\subsection{Market Concentration in Scooter segment}

The computation of measures of concentration in Scooter segment of two wheeler industry in India has been shown in Table 1. The major players in Scooter segment in India include Hero Motocorp Ltd., Honda Motorcycle \& Scooter India Pvt. Ltd., India Yamaha Motor Pvt. Ltd., Mahindra Two Wheelers Ltd., Piaggio Vehicles Pvt. Ltd., Suzuki Motorcycle India Pvt. Ltd. and TVS Motor Co. Ltd. A trend of 4-firm Concentration Ratio, Herfindahl-Hirschman Index and Entropy Index for market concentration in Scooter segment is shown in Figure 1.

It can be seen in Table 1 that there are high values of 4-firm Concentration Ratio for all years under observation, i.e., 2011-12 through 2018-19 which indicate that there is a presence of high level of concentration in Scooter segment. The value of 4-firm Concentration Ratio decreased from 0.947 in the year 2011-12 to 0.931 in the year 2013-14. Further, the value of 4-firm Concentration Ratio increased to 0.935 in the year 2014-15, reduced to 0.926 in the year 201718. The value of 4-firm Concentration Ratio ultimately increased to 0.934 in the year 2018-19. Overall, the 4-firm Concentration Ratio decreased from 0.947 in the year 2011-12 to 0.934 in the year 2018-19.

Further, as can be seen in Table 1, there are high values of Herfindahl-Hirschman Index for all years under observation, i.e., 2011-12 through 2018-19 which indicate that there is a presence of high level of concentration in Scooter segment. Figure 1 shows that the value of HerfindahlHirschman Index decreased from 3,084.12 in the year 2011-12 to 3,068.56 in the year 201213. It then rose to 3,411.90 in the year 2013-14. Further, as can be seen in Figure 1, HerfindahlHirschman Index increased from 3,411.90 in the year 2013-14 to 3,656.04 in the year 2014-15 to 3,637.02 in the year 2015-16. Moreover, the values of Herfindahl-Hirschman Index went on to increase to 3,741.46 in the year 2016-17 and 3,753.32 in the year 2017-18. But, the value of Herfindahl-Hirschman Index reduced to 3,589.54 in the year 2018-19. 
There are low values of Entropy Index throughout from the year 2011-12 to the year 2018-19 which shows that there is an existence of oligopoly structure of market as there is concentration of sales in the hands of few sellers in the market. The value of Entropy Index increased from 0.594 in year 2011-12 to 0.627 in year 2012-13 due to addition of new sellers. Overall, the values of Entropy Index reduced from 0.594 in the year 2011-12 to 0.571 in the year 2018-19 with slight fluctuations in between these years.

To conclude, there is oligopoly structure of market in Scooter segment of two wheeler industry in India for a time period of eight years from the year 2011-12 to the year 2018-19.

Table 1: Market Concentration in Scooter segment

\begin{tabular}{|l|r|r|r|r|r|r|r|r|}
\hline \multirow{2}{*}{ COMPANY / YEAR } & \multicolumn{7}{|c|}{ MARKET SHARE (\%) } \\
\cline { 2 - 9 } & $\mathbf{2 0 1 1 - 1 2}$ & $\mathbf{2 0 1 2 - 1 3}$ & $\mathbf{2 0 1 3 - 1 4}$ & $\mathbf{2 0 1 4 - 1 5}$ & $\mathbf{2 0 1 5 - 1 6}$ & $\mathbf{2 0 1 6 - 1 7}$ & $\mathbf{2 0 1 7 - 1 8}$ & $\mathbf{2 0 1 8 - 1 9}$ \\
\hline Hero MotoCorp Ltd. & 16.19 & 18.81 & 19.15 & 16.69 & 16.27 & 14.10 & 13.15 & 10.73 \\
\hline $\begin{array}{l}\text { Honda Motorcycle \& Scooter } \\
\text { India Pvt. Ltd. }\end{array}$ & 47.85 & 48.58 & 52.82 & 55.54 & 55.44 & 56.90 & 56.87 & 54.92 \\
\hline India Yamaha Motor Pvt. Ltd. & - & 2.06 & 4.91 & 4.82 & 6.33 & 7.86 & 6.18 & 5.44 \\
\hline Mahindra Two Wheelers Ltd. & 5.26 & 3.47 & 1.31 & 1.03 & 1.67 & 0.61 & 0.16 & 0.05 \\
\hline Piaggio Vehicles Pvt. Ltd. & - & 1.32 & 0.88 & 0.62 & 0.53 & 0.78 & 1.01 & 1.16 \\
\hline Suzuki Motorcycle India Pvt. Ltd. & 11.28 & 11.25 & 8.24 & 6.11 & 4.38 & 5.01 & 6.27 & 9.18 \\
\hline TVS Motor Company Ltd. & 19.42 & 14.51 & 12.68 & 15.19 & 15.37 & 14.74 & 16.36 & 18.52 \\
\hline Total: Scooters & $\mathbf{1 0 0 . 0 0}$ & $\mathbf{1 0 0 . 0 0}$ & $\mathbf{1 0 0 . 0 0}$ & $\mathbf{1 0 0 . 0 0}$ & $\mathbf{1 0 0 . 0 0}$ & $\mathbf{1 0 0 . 0 0}$ & $\mathbf{1 0 0 . 0 0}$ & $\mathbf{1 0 0 . 0 0}$ \\
\hline 4-Firm Concentration Ratio & $\mathbf{0 . 9 4 7}$ & $\mathbf{0 . 9 3 1}$ & $\mathbf{0 . 9 2 9}$ & $\mathbf{0 . 9 3 5}$ & $\mathbf{0 . 9 3 4}$ & $\mathbf{0 . 9 3 6}$ & $\mathbf{0 . 9 2 6}$ & $\mathbf{0 . 9 3 4}$ \\
\hline Herfindahl-Hirschman Index & $\mathbf{3 , 0 8 4 . 1 2}$ & $\mathbf{3 , 0 6 8 . 5 6}$ & $\mathbf{3 , 4 1 1 . 9 0}$ & $\mathbf{3 , 6 5 6 . 0 4}$ & $\mathbf{3 , 6 3 7 . 0 2}$ & $\mathbf{3 , 7 4 1 . 4 6}$ & $\mathbf{3 , 7 5 3 . 3 2}$ & $\mathbf{3 , 5 8 9 . 5 4}$ \\
\hline Entropy Index & $\mathbf{0 . 5 9 4}$ & $\mathbf{0 . 6 2 7}$ & $\mathbf{0 . 5 9 4}$ & $\mathbf{0 . 5 6 8}$ & $\mathbf{0 . 5 7 3}$ & $\mathbf{0 . 5 6 4}$ & $\mathbf{0 . 5 5 9}$ & $\mathbf{0 . 5 7 1}$ \\
\hline
\end{tabular}

Source: Society of Indian Automobile Manufacturers (SIAM)

- denotes data not available
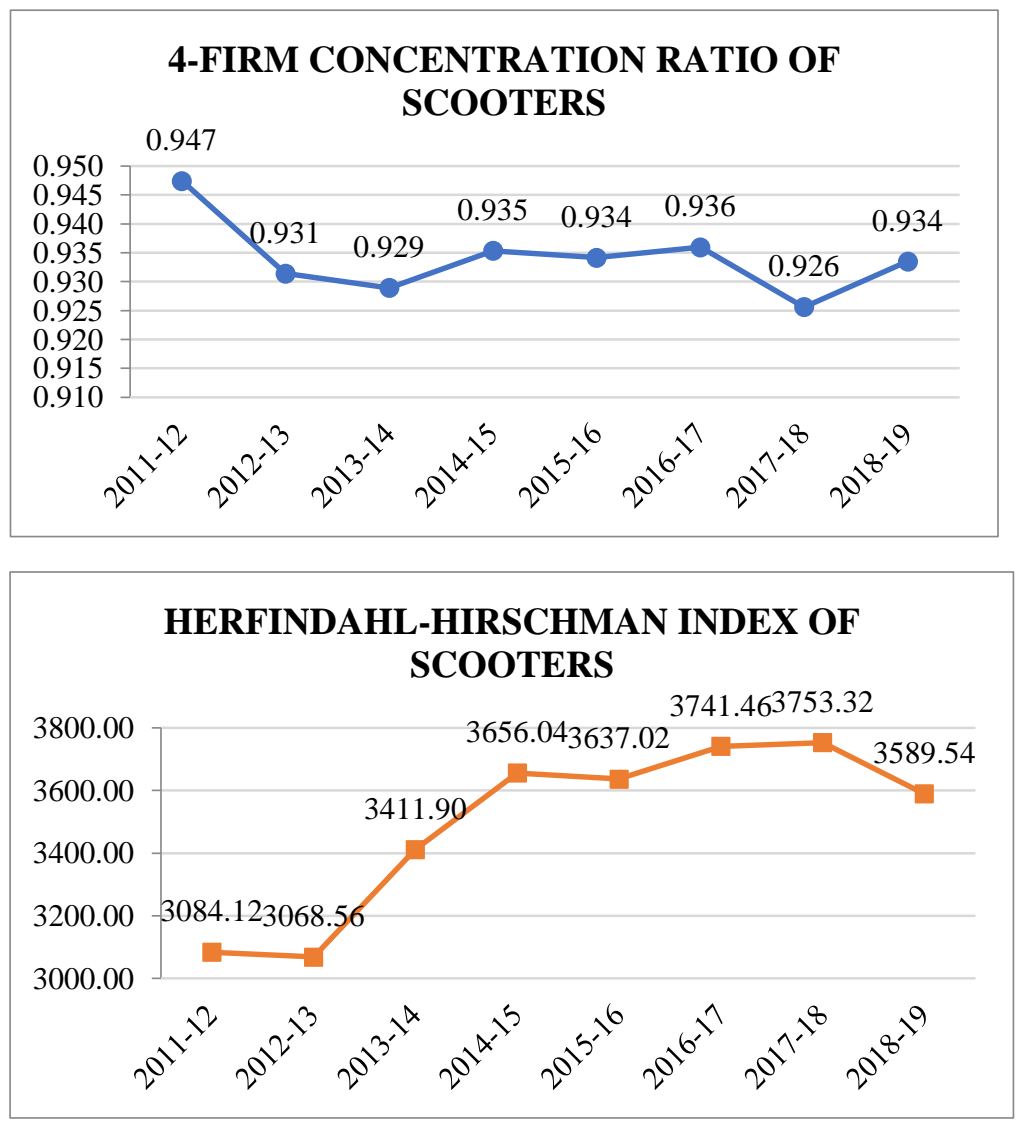


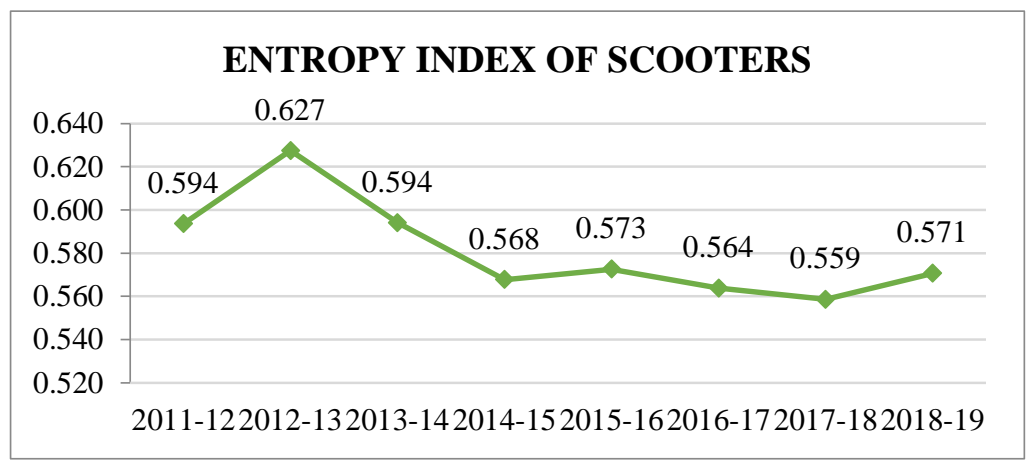

Subsequent sections show measurement of Market Concentration in multiple categories of Scooter segment on the basis of engine capacity (cc). Four categories in the Scooter segment are as follows:

1. Scooter category with engine capacity $\leq 75 \mathrm{cc}$

2. Scooters category with engine capacity $>75 \mathrm{cc}$ but $\leq 90 \mathrm{cc}$

3. Scooter category with engine capacity $>90 \mathrm{cc}$ but $\leq 125 \mathrm{cc}$

4. Scooter category with engine capacity $>125 \mathrm{cc}$ but $\leq 150 \mathrm{cc}$

\subsection{Market Concentration in Scooter segment (Engine capacity $\leq 75 \mathrm{cc}$ )}

The computation of measures of concentration for Scooter segment of Two Wheeler Industry in India in the category of engine capacity $\leq 75 \mathrm{cc}$ is shown in Table 2 . There are two major competing players in this category, namely, Mahindra Two Wheelers Ltd. and TVS Motor Co. Ltd. A trend of 4-firm Concentration Ratio, Herfindahl-Hirschman Index and Entropy Index for market concentration in Scooter category with engine capacity $\leq 75 \mathrm{cc}$ is shown in Figure 2 .

As can be seen in Table 2, there are high levels of concentration in Scooter category with engine capacity $\leq 75 \mathrm{cc}$. As be seen in Figure 2, there are high values of 4-firm Concentration Ratio for all years under observation, i.e., from 2011-12 through 2015-16 which indicates that there is a presence of high concentration in the category of Scooter category with engine capacity $\leq$ $75 \mathrm{cc}$. The value of 4-firm Concentration Ratio has been at 1.00 from the year 2011-12 through the year 2015-16.

Further, the high values of Herfindahl-Hirschman Index for all years under observation, i.e. from year 2011-12 to year 2015-16 also indicate that there is a presence of high concentration in the Scooter category with engine capacity $\leq 75 \mathrm{cc}$. As can be seen in Table 2, HerfindahlHirschman Index increased from 6,243.01 in the year 2011-12 to 10,000 in the year 2015-16.

There are low values of Entropy Index which indicate high concentration in the market in this category. It shows that there is an existence of duopoly form of market from the years 2011-12 to 2013-14 as there is concentration of sales in the hands of two sellers in the market but there is a change in the form of market to monopoly because there is only one seller in the market for the two years, i.e., 2014-15 and 2015-16. The values of Entropy Index are at 0.000 each for two years, i.e. 2014-15 and 2015-16. The values of Entropy Index for year 2011-12 was 0.245, 0.240 in the year 2012-13 and 0.107 in the year 2013-14. 
To conclude, there is an existence of duopoly form of market from the years 2011-12 to 2013-14 but there is a change in the structure of market to monopoly form of market structure because of presence of single seller only in the category of engine capacity $\leq 75$ cc in the scooter segment of two wheeler industry in India.

Table 2: Market Concentration in Scooter segment

(Engine capacity $\leq 75 \mathrm{cc}$ )

\begin{tabular}{|l|r|r|r|r|r|r|r|r|}
\hline \multirow{2}{*}{ COMPANY / YEAR } & \multicolumn{9}{|c|}{ MARKET SHARE (\%) } \\
\cline { 2 - 9 } & $\mathbf{2 0 1 1 - 1 2}$ & $\mathbf{2 0 1 2 - 1 3}$ & $\mathbf{2 0 1 3 - 1 4}$ & $\mathbf{2 0 1 4 - 1 5}$ & $\mathbf{2 0 1 5 - 1 6}$ & $\mathbf{2 0 1 6 - 1 7}$ & $\mathbf{2 0 1 7 - 1 8}$ & $\mathbf{2 0 1 8 - 1 9}$ \\
\hline Mahindra Two Wheelers Ltd. & 25.07 & 75.84 & 93.27 & 100.00 & 100.00 & - & - & - \\
\hline TVS Motor Company Ltd. & 74.93 & 24.16 & 6.73 & - & - & - & - & - \\
\hline Total & $\mathbf{1 0 0 . 0 0}$ & $\mathbf{1 0 0 . 0 0}$ & $\mathbf{1 0 0 . 0 0}$ & $\mathbf{1 0 0 . 0 0}$ & $\mathbf{1 0 0 . 0 0}$ & - & - & - \\
\hline 4-Firm Concentration Ratio & $\mathbf{1 . 0 0 0}$ & $\mathbf{1 . 0 0 0}$ & $\mathbf{1 . 0 0 0}$ & $\mathbf{1 . 0 0 0}$ & $\mathbf{1 . 0 0 0}$ & - & - & - \\
\hline Herfindahl-Hirschman Index & $\mathbf{6 , 2 4 3 . 0 1}$ & $\mathbf{6 , 3 3 5 . 4 1}$ & $\mathbf{8 , 7 4 5 . 3 0}$ & $\mathbf{1 0 , 0 0 0 . 0 0}$ & $\mathbf{1 0 , 0 0 0 . 0 0}$ & - & - & - \\
\hline Entropy Index & $\mathbf{0 . 2 4 5}$ & $\mathbf{0 . 2 4 0}$ & $\mathbf{0 . 1 0 7}$ & $\mathbf{0 . 0 0 0}$ & $\mathbf{0 . 0 0 0}$ & - & - & - \\
\hline
\end{tabular}

Source: Society of Indian Automobile Manufacturers (SIAM)

- denotes data not available
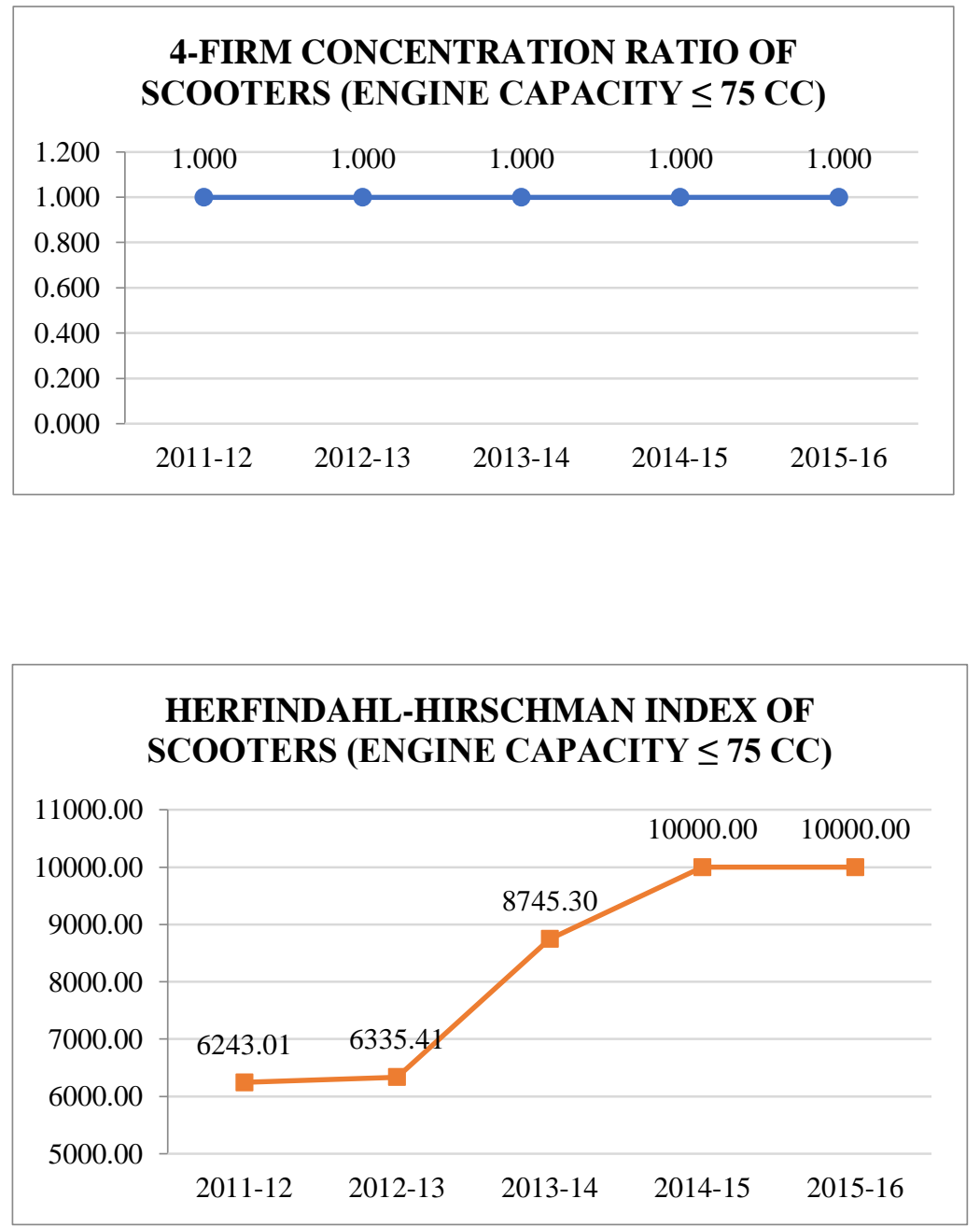


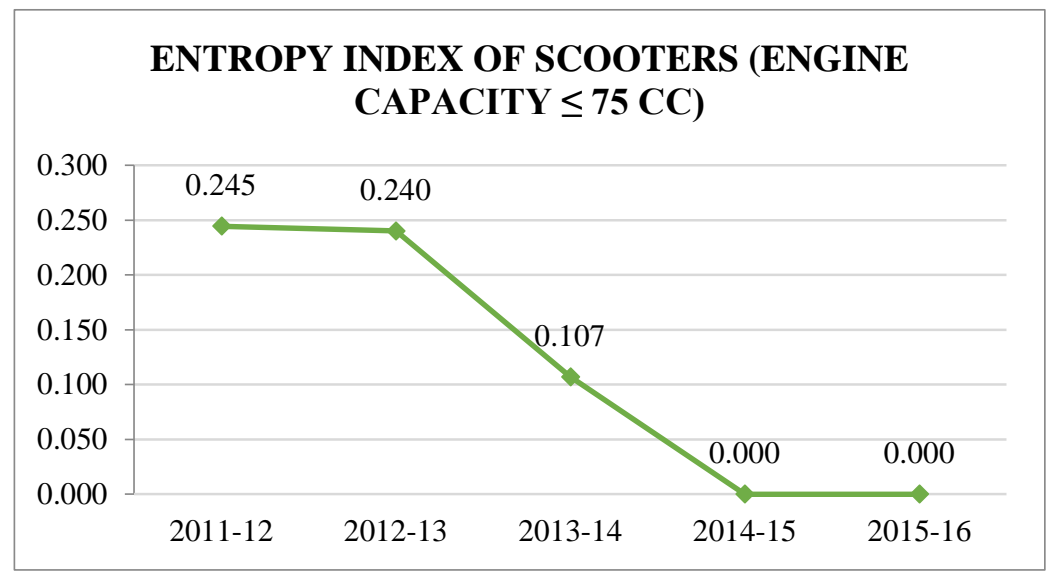

Figure 2: Market Concentration in Scooter segment

(Engine capacity $\leq 75 \mathrm{cc}$ )

\subsection{Market Concentration in Scooter segment (Engine capacity $>75$ cc but $\leq 90 \mathrm{cc}$ )}

The calculation of measures of concentration in Scooter segment with engine capacity $>75 \mathrm{cc}$ but $\leq 90 \mathrm{cc}$ of Two Wheeler Industry in India is shown in Table 3. There is only one major player in this category, i.e., TVS Motor Co. Ltd. A trend of 4-firm Concentration Ratio, Herfindahl-Hirschman Index and Entropy Index for market concentration in Scooter category with engine capacity $>75 \mathrm{cc}$ but $\leq 90 \mathrm{cc}$ is shown in Figure 3 .

As shown in Table 3 and Figure 3, the value of 4-firm Concentration Ratio is 1.000 and the value of Herfindahl-Hirschman Index is 10,000 . There is a constant value of 0.000 of Entropy Index throughout indicating existence of monopoly form of market. As can be seen in Table 3 and Figure 3, there is complete concentration in this category. It shows that there is an existence of monopoly form of market structure by TVS Motor Co. Ltd. in scooter category with engine capacity $>75 \mathrm{cc}$ but $\leq 90 \mathrm{cc}$ from the year 2011-12 through the year 2018-19.

To conclude, there is an existence of monopoly form of market structure in the category with engine capacity $>75$ cc but $\leq 90$ cc of scooter segment for a period of eight years from the year 2011-12 to the year 2018-19.

Table 3: Market concentration in scooter segment

(Engine capacity $>75$ cc but $\leq 90$ cc)

\begin{tabular}{|l|r|r|r|r|r|r|r|r|}
\hline \multirow{2}{*}{ COMPANY / YEAR } & \multicolumn{10}{|c|}{ MARKET SHARE (\%) } \\
\cline { 2 - 9 } & $\mathbf{2 0 1 1 - 1 2}$ & $\mathbf{2 0 1 2 - 1 3}$ & $\mathbf{2 0 1 3 - 1 4}$ & $\mathbf{2 0 1 4 - 1 5}$ & $\mathbf{2 0 1 5 - 1 6}$ & $\mathbf{2 0 1 6 - 1 7}$ & $\mathbf{2 0 1 7}-\mathbf{1 8}$ & $\mathbf{2 0 1 8}-19$ \\
\hline TVS Motor Co. Ltd. & 100 & 100 & 100 & 100 & 100 & 100 & 100 & 100 \\
\hline Total & 100 & 100 & 100 & 100 & 100 & 100 & 100 & 100 \\
\hline 4-Firm Concentration Ratio & 1.000 & 1.000 & 1.000 & 1.000 & 1.000 & 1.000 & 1.000 & 1.000 \\
\hline Herfindahl-Hirschman Index & $\mathbf{1 0 , 0 0 0}$ & $\mathbf{1 0 , 0 0 0}$ & $\mathbf{1 0 , 0 0 0}$ & $\mathbf{1 0 , 0 0 0}$ & $\mathbf{1 0 , 0 0 0}$ & $\mathbf{1 0 , 0 0 0}$ & $\mathbf{1 0 , 0 0 0}$ & $\mathbf{1 0 , 0 0 0}$ \\
\hline Entropy Index & $\mathbf{0 . 0 0 0}$ & $\mathbf{0 . 0 0 0}$ & $\mathbf{0 . 0 0 0}$ & $\mathbf{0 . 0 0 0}$ & $\mathbf{0 . 0 0 0}$ & $\mathbf{0 . 0 0 0}$ & $\mathbf{0 . 0 0 0}$ & $\mathbf{0 . 0 0 0}$ \\
\hline
\end{tabular}

Source: Society of Indian Automobile Manufacturers (SIAM)

- denotes data not available 

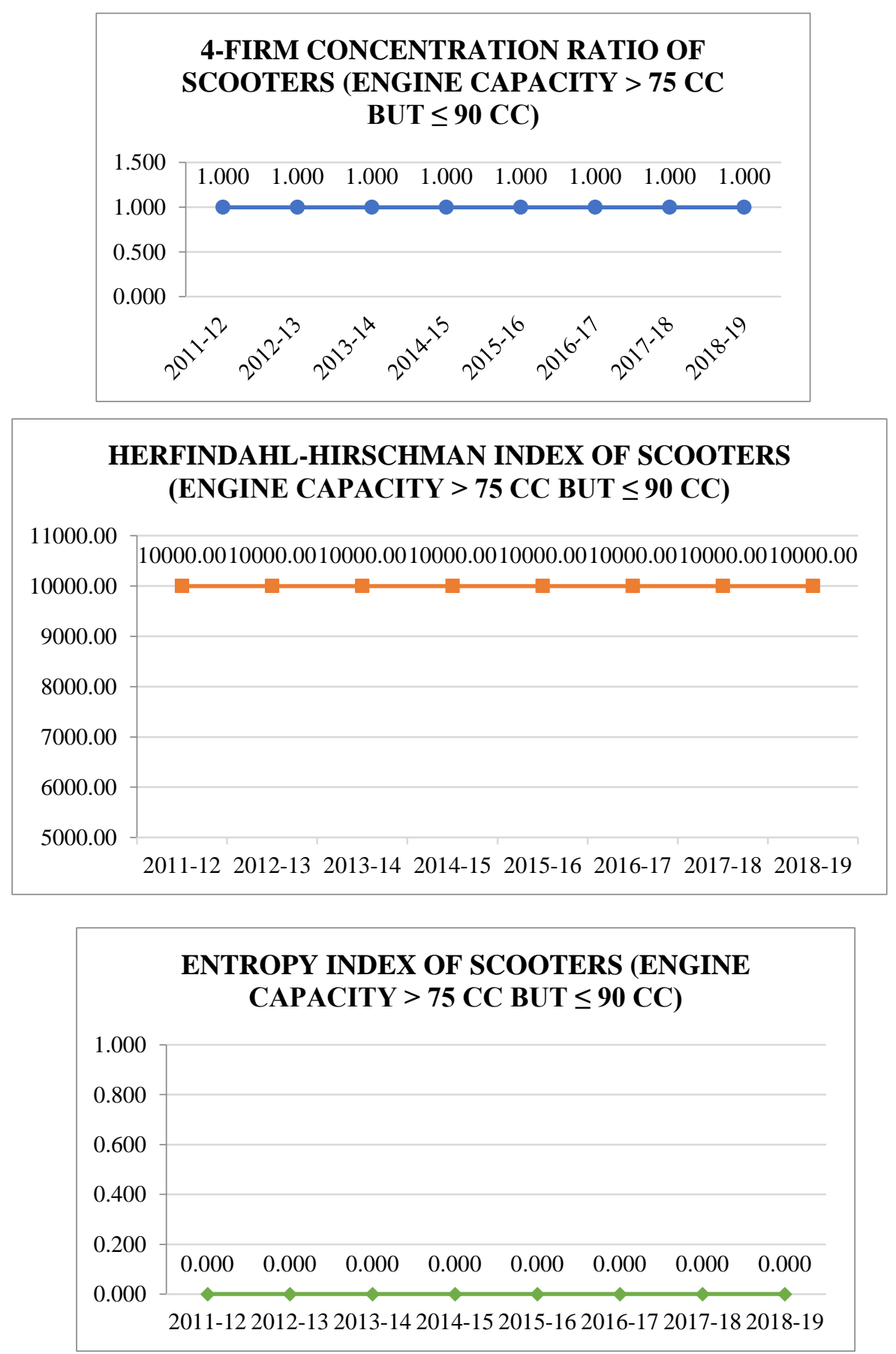

Figure 3: Market Concentration in Scooter segment (Engine capacity $>75$ cc but $\leq 90 \mathrm{cc}$ )

3.4 Market Concentration in Scooter segment (Engine capacity $>90$ cc but $\leq 125 \mathrm{cc}$ ) The calculation of measures of concentration for Scooter segment in the category of engine capacity $>90 \mathrm{cc}$ but $\leq 125 \mathrm{cc}$ in India is shown in Table 4. The major players in Scooter segment in this category include Hero Motocorp Ltd., Honda Motorcycle \& Scooter India Pvt. Ltd., India Yamaha Motor Pvt. Ltd., Mahindra Two Wheelers Ltd., Piaggio Vehicles Pvt. Ltd., Suzuki Motorcycle India Pvt. Ltd. and TVS Motor Co. Ltd. A trend of 4-firm Concentration 
Ratio, Herfindahl-Hirschman Index and Entropy Index for market concentration in Scooter category with engine capacity $>90 \mathrm{cc}$ but $\leq 125 \mathrm{cc}$ is shown in Figure 4 .

As can be seen in Table 4 and Figure 4, there are high levels of concentration in the Scooter category with engine capacity $>90 \mathrm{cc}$ but $\leq$ to $125 \mathrm{cc}$. It can be seen in Table 4 , there are high values of 4-firm Concentration Ratio for all years under observation, i.e., 2011-12 through 2018-19 which indicate that there is a presence of high concentration in this category of Scooter segment. The value of 4-firm Concentration Ratio decreased to 0.926 in the year 2012-13 from 0.942 in the year 2011-12. Further, the value of 4-firm Concentration Ratio increased in the year 2014-15 to 0.932. The 4-firm Concentration Ratio increased from 0.932 in the year 201415 to 0.939 in the year 2016-17. Further, the value of 4-firm Concentration Ratio decreased to 0.930 in the year 2017-18 and again rose up to 0.937 in the year 2018-19. Overall, the 4-firm Concentration Ratio decreased from 0.942 in the year 2011-12 to 0.937 in the year 2018-19.

Further, the high values of Herfindahl-Hirschman Index for all years under observation, i.e., from year 2011-12 to year 2018-19 also indicate that there is a presence of high concentration in this category of Scooter segment. As can be seen in Table 4, Herfindahl-Hirschman Index decreased from 3,556.88 in the year 2011-12 to 3,460.24 in the year 2012-13. It then increased to 3,699.20 in the year 2013-14. Further, Herfindahl-Hirschman Index increased from 3,699.20 in the year 2013-14 to 3,874.31 in the year 2014-15. Further, Herfindahl-Hirschman Index decreased to 3,719.73 in the year 2015-16 and then again increased to 3,864.55 in the year 2016-17. Further, there was an increase in the value of Herfindahl-Hirschman Index to 3,892.08 in the year 2017-18 and then a decrease to 3,706.93 in the year 2018-19. Herfindahl-Hirschman Index values for Scooter segment in the category of engine capacity $>90 \mathrm{cc}$ but $\leq 125 \mathrm{cc}$ kept on fluctuating for the time period from the year 2011-12 through the year 2018-19 but overall, it increased from 3,556.88 in the year 2011-12 to 3,706.93 in the year 2018-19.

There are low values of Entropy Index throughout from the year 2011-12 to the year 2018-19 signifying high levels of market concentration. The value of Entropy Index increased from 0.558 in the year 2011-12 to 0.594 in the year 2012-13. But, it reduced to 0.570 in the year 2013-14 and further reduced to 0.553 in the year 2014-15. The value of Entropy Index increased to 0.566 in the year $2015-16$ but reduced further to 0.550 in the year 2016-17. In the year 2017-18, the value of Entropy Index again fell down to 0.475 but increased to 0.559 in the year 2018-19. Overall, the value of Entropy Index remained nearly the same at a value of 0.558 in the year 2011-12 and at 0.559 in the year 2018-19 with slight fluctuations in values in between these years. It shows that there is an existence of oligopoly structure of market as there is concentration of sales in the hands of few sellers in the market.

To conclude, there is an existence of oligopoly form of market structure in category with engine capacity $>90$ cc but $\leq 125$ cc in scooters segment for a period of eight years from the year 2011-12 to the year 2018-19. 
Table 4: Market Concentration in Scooter segment

(Engine capacity $>90$ cc but $\leq 125$ cc)

\begin{tabular}{|l|r|r|r|r|r|r|r|r|}
\hline \multirow{2}{*}{ COMPANY / YEAR } & \multicolumn{7}{|c|}{ MARKET SHARE (\%) } \\
\cline { 2 - 9 } & $\mathbf{2 0 1 1 - 1 2}$ & $\mathbf{2 0 1 2 - 1 3}$ & $\mathbf{2 0 1 3 - 1 4}$ & $\mathbf{2 0 1 4 - 1 5}$ & $\mathbf{2 0 1 5 - 1 6}$ & $\mathbf{2 0 1 6 - 1 7}$ & $\mathbf{2 0 1 7 - 1 8}$ & $\mathbf{2 0 1 8 - 1 9}$ \\
\hline Hero MotoCorp Ltd. & 18.36 & 20.56 & 20.27 & 17.46 & 16.57 & 14.42 & 13.51 & 11.02 \\
\hline $\begin{array}{l}\text { Honda Motorcycle \& Scooter } \\
\text { India Pvt. Ltd. }\end{array}$ & 54.27 & 53.12 & 55.90 & 58.09 & 56.45 & 58.22 & 58.42 & 56.40 \\
\hline India Yamaha Motor Pvt. Ltd. & - & 2.25 & 5.20 & 5.04 & 6.44 & 8.04 & 6.35 & 5.59 \\
\hline Mahindra Two Wheelers Ltd. & 5.76 & 3.73 & 1.36 & 1.07 & 1.70 & 0.63 & 0.16 & 0.04 \\
\hline Piaggio Vehicles Pvt. Ltd. & - & 1.45 & 0.94 & 0.65 & 0.45 & 0.33 & 0.47 & 0.66 \\
\hline Suzuki Motorcycle India Pvt. Ltd. & 12.79 & 12.3 & 8.72 & 6.39 & 4.46 & 5.13 & 6.44 & 9.43 \\
\hline TVS Motor Company Ltd. & 8.82 & 6.59 & 7.61 & 11.31 & 13.92 & 13.23 & 14.65 & 16.85 \\
\hline Total & $\mathbf{1 0 0 . 0 0}$ & $\mathbf{1 0 0 . 0 0}$ & $\mathbf{1 0 0 . 0 0}$ & $\mathbf{1 0 0 . 0 0}$ & $\mathbf{1 0 0 . 0 0}$ & $\mathbf{1 0 0 . 0 0}$ & $\mathbf{1 0 0 . 0 0}$ & $\mathbf{1 0 0 . 0 0}$ \\
\hline 4-Firm Concentration Ratio & $\mathbf{0 . 9 4 2}$ & $\mathbf{0 . 9 2 6}$ & $\mathbf{0 . 9 2 5}$ & $\mathbf{0 . 9 3 2}$ & $\mathbf{0 . 9 3 4}$ & $\mathbf{0 . 9 3 9}$ & $\mathbf{0 . 9 3 0}$ & $\mathbf{0 . 9 3 7}$ \\
\hline Herfindahl-Hirschman Index & $\mathbf{3 , 5 5 6 . 8 8}$ & $\mathbf{3 , 4 6 0 . 2 4}$ & $\mathbf{3 , 6 9 9 . 2 0}$ & $\mathbf{3 , 8 7 4 . 3 1}$ & $\mathbf{3 , 7 1 9 . 7 3}$ & $\mathbf{3 , 8 6 4 . 5 5}$ & $\mathbf{3 , 8 9 2 . 0 8}$ & $\mathbf{3 , 7 0 6 . 9 3}$ \\
\hline Entropy Index & $\mathbf{0 . 5 5 8}$ & $\mathbf{0 . 5 9 4}$ & $\mathbf{0 . 5 7 0}$ & $\mathbf{0 . 5 5 3}$ & $\mathbf{0 . 5 6 6}$ & $\mathbf{0 . 5 5 0}$ & $\mathbf{0 . 4 7 5}$ & $\mathbf{0 . 5 5 9}$ \\
\hline
\end{tabular}

Source: Society of Indian Automobile Manufacturers (SIAM)

- denotes data not available
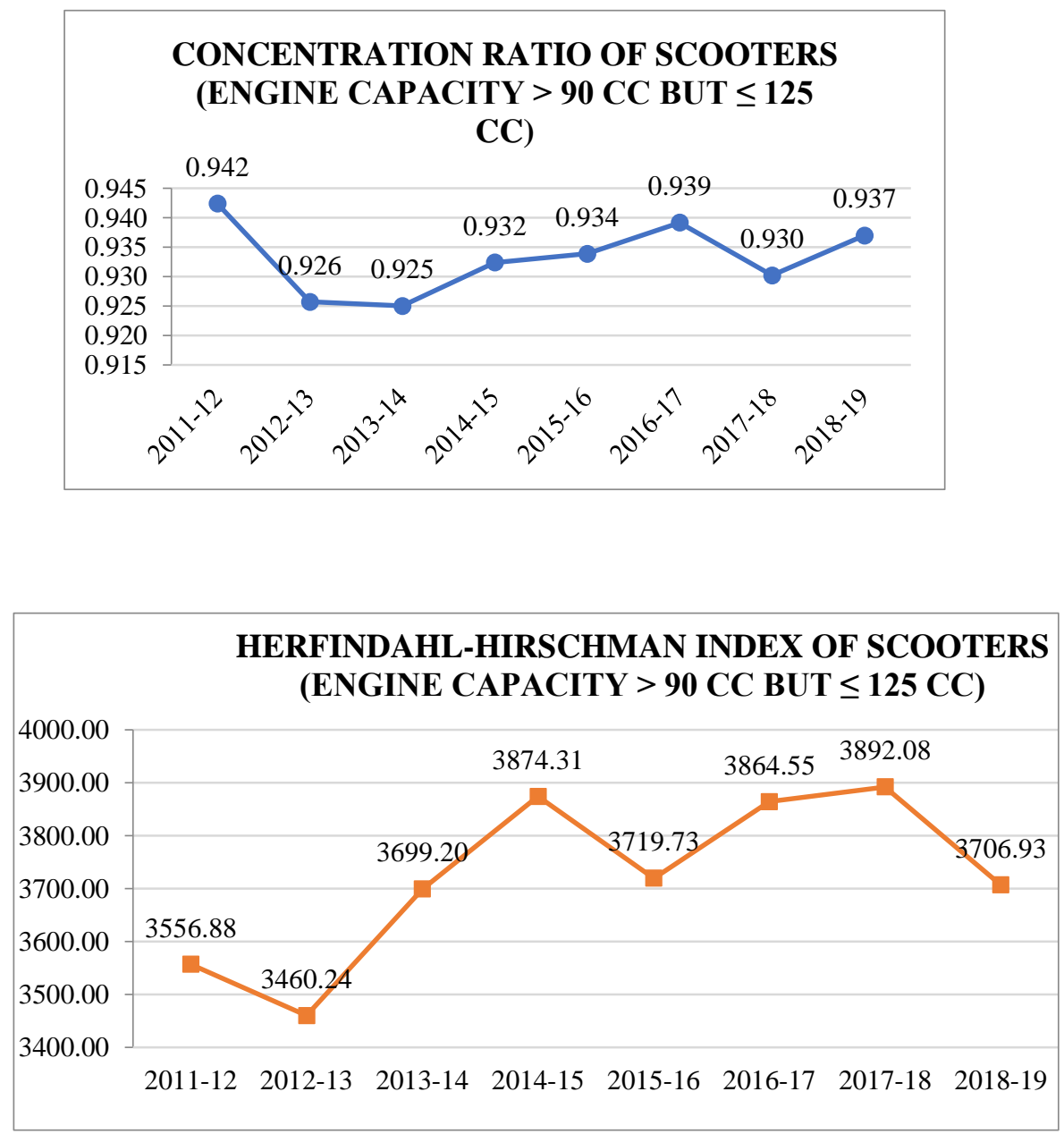


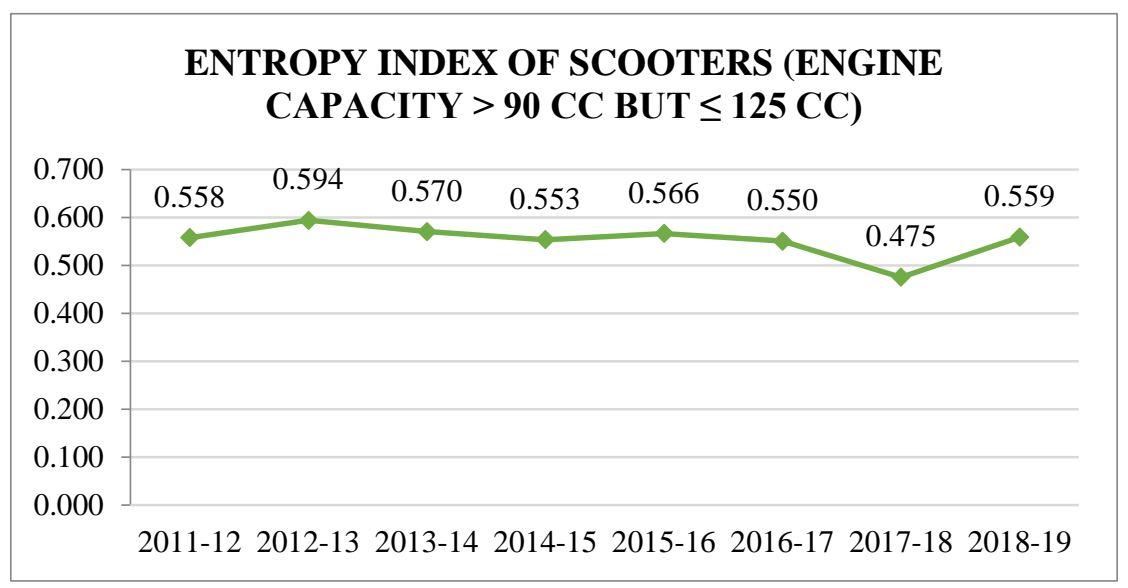

Figure 4: Market Concentration in Scooter segment

(Engine capacity $>90$ cc but $\leq 125$ cc)

\subsection{Market Concentration in Scooter segment (Engine capacity $>125$ cc but $\leq 150 \mathrm{cc}$ )}

The calculation of measures of concentration for scooters in the category of engine capacity $>$ $125 \mathrm{cc}$ but $\leq 150 \mathrm{cc}$ in India is shown in Table 5. Piaggio Vehicles Pvt. Ltd. is the only seller in Scooter segment in the category of engine capacity $>125 \mathrm{cc}$ but $\leq 150 \mathrm{cc}$. A trend of 4-firm Concentration Ratio, Herfindahl-Hirschman Index and Entropy Index for market concentration in Scooter category with engine capacity $>125 \mathrm{cc}$ but $\leq 150 \mathrm{cc}$ is shown in Figure 5.

It can be seen in Table 5 and Figure 5 that there is high value of 4-firm Concentration Ratio for all years under observation, i.e., 2015-16 through 2018-19 which indicates that there is a presence of high level of concentration in Scooter segment in the category of engine capacity $>125 \mathrm{cc}$ but $\leq 150 \mathrm{cc}$. The value of 4 -firm Concentration Ratio is 1.000 and the value of Herfindahl-Hirschman Index is 10,000 throughout from year 2015-16 to year 2018-19. The value of Entropy Index at 0.000 throughout from year 2015-16 to year 2018-19 depicts very high level of market concentration. It shows that there is an existence of monopoly structure of market in category of scooters with engine capacity $>125 \mathrm{cc}$ but $\leq 150 \mathrm{cc}$ as Piaggio Vehicles Pvt. Ltd. is the only seller in this category.

To conclude, there is an existence of monopoly form of market structure in the category with engine capacity $>125$ cc but $\leq 150$ cc of scooters segment for four years from the year 2015-16 to the year 2018-19.

Table 5: Market Concentration in Scooter segment (Engine capacity $>125$ cc but $\leq 150$ cc)

\begin{tabular}{|c|c|c|c|c|c|c|c|c|}
\hline \multirow{2}{*}{ COMPANY / YEAR } & \multicolumn{8}{|c|}{ MARKET SHARE (\%) } \\
\hline & 2011-12 & 2012-13 & 2013-14 & 2014-15 & 2015-16 & 2016-17 & 2017-18 & 2018-19 \\
\hline Piaggio Vehicles Pvt. Ltd. & - & - & - & - & 100 & 100 & 100 & 100 \\
\hline Total & - & - & - & - & 100 & 100 & 100 & 100 \\
\hline 4-Firm Concentration Ratio & - & - & - & - & 1.000 & 1.000 & 1.000 & 1.000 \\
\hline Herfindahl-Hirschman Index & - & - & - & - & 10,000 & 10,000 & 10,000 & 10,000 \\
\hline Entropy Index & - & - & - & - & 0.000 & 0.000 & 0.000 & 0.000 \\
\hline
\end{tabular}



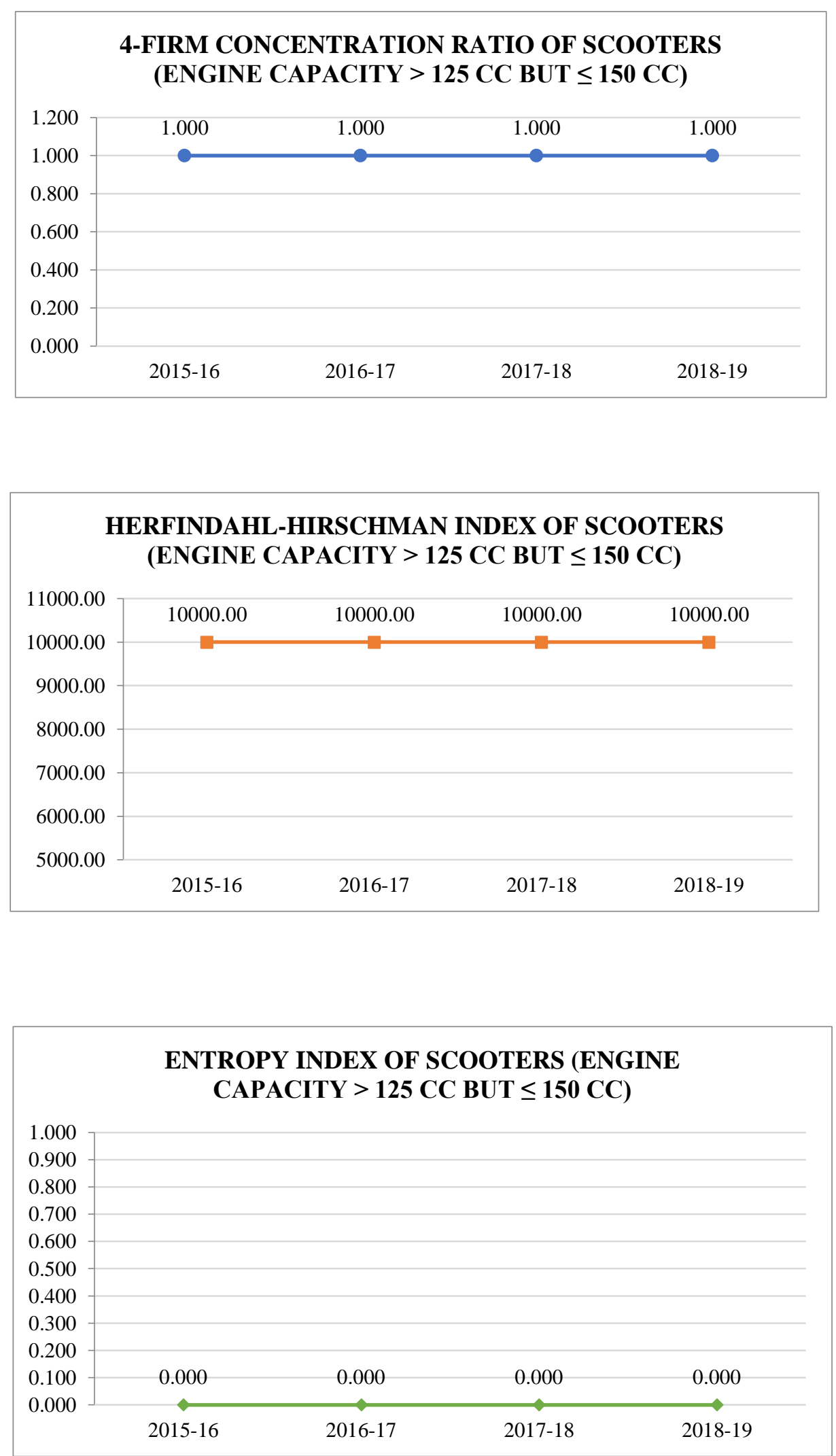

Figure 5: Market Concentration in Scooter segment

(Engine capacity $>125$ cc but $\leq 150$ cc) 


\section{Conclusion and Managerial Implications}

Table 6 concludes the forms of market structure for Scooter segment overall and also for multiple categories of Scooter segment on the basis of engine capacity (cc) for a time period of eight financial years from the year 2011-12 to the year 2018-19. The elaborate analysis of competitive intensity and competitive landscape of two wheeler industry in India conveys the extent of competition and scope for exploring new business opportunities. Furthermore, the analysis of market structure segregated into the four categories of scooter segment based on engine capacity along with the overall competitive landscape of scooter segment gives a clearer picture to managers to construct their strategies.

Table 6: Forms of market structure for Scooter segment and multiple categories of Scooter segment on the basis of engine capacity

\begin{tabular}{|l|c|c|}
\hline \multicolumn{1}{|c|}{ Segment / Category } & \multicolumn{1}{c|}{ Time period } & Form of market structure \\
\hline Scooter segment $($ Overall) & $2011-12$ to $2018-19$ & Oligopoly \\
\hline $\begin{array}{l}\text { Scooter } \\
\text { (Engine capacity } \leq 75 \mathrm{cc} \text { ) }\end{array}$ & $2011-12$ to $2013-14$ & Duopoly \\
\cline { 2 - 3 } $\begin{array}{l}\text { Scooter } \\
(\text { Engine capacity }>75 \mathrm{cc} \text { but } \leq 90 \mathrm{cc} \text { ) }\end{array}$ & $2014-15$ to $2015-16$ & Monopoly \\
\hline $\begin{array}{l}\text { Scooter } \\
(\text { Engine capacity }>90 \mathrm{cc} \text { but } \leq 125 \mathrm{cc} \text { ) }\end{array}$ & $2011-12$ to $2018-19$ & Oligopoly \\
\hline $\begin{array}{l}\text { Scooter } \\
\text { (Engine capacity }>125 \mathrm{cc} \text { but } \leq 150 \mathrm{cc} \text { ) }\end{array}$ & $2015-16$ to $2018-19$ & Monopoly \\
\hline
\end{tabular}

\section{References}

[1] Besanko, D., Dranove, D., Shanley, M., \& Schaefer, S. (2013). Economics of Strategy (Sixth ed.). John Wiley \& Sons.

[2] Ferguson, P. R., \& Ferguson, G. J. (1994). Market Concentration. In P. R. Ferguson, \& G. J. Ferguson, Industrial Economics: Issues and Perspectives (2nd ed., pp. 38-59). Palgrave Macmillan.

[3] India, G. o. (2016). Automotive Mission Plan: 2016-26 (A Curtain Raiser). Government of India. Retrieved from http://www.siam.in/uploads/filemanager/47AUTOMOTIVEMISSIONPLAN.pdf

[4] Jacquemin, A. P., \& Berry, C. H. (1979). Entropy Measure of Diversification and Corporate Growth. The Journal of Industrial Economics, 27(4), 359-369.

[5] Kramaric, T. P., \& Kitic, M. (2012). Comparative Analysis of Concentration in Insurance Markets in New EU Member States. International Journal of Social, Behavioural, Educational,Economic, Business and Industrial Engineering, 6(6), 13221326. 
[6] Porter, M. E. (1979, March - April). How Competitive Forces Shape Strategy. Harvard Business Review, 57(2), 137-145.

[7] Porter, M. E. (1981). The Contributions of Industrial Organisation To Strategic Management. Academy of Management Review, 6(4), 609-620.

[8] Porter, M. E. (1983). Industrial Organisation and the Evolution of Concepts for Strategic Planning: The New Learning. Managerial and Decision Economics, 4(3), 172-180.

[9] White, A. P. (1982, October). A Note on Market Structure Measures and the Characteristics of Markets That They "Measure". Southern Economic Journal, 49(2), 542-549. 